\title{
Linfangioma mesentérico multiquístico como causa de vólvulo intestinal*
}

\author{
Drs. RICARDO YÁÑEZ M. ${ }^{1}$, XIMENA PARADA D. ${ }^{2}$, MARIO DA VENEZIA R. ${ }^{2}$, \\ Int. LUIS VALDIVIA V. ${ }^{3}$, Drs. CRISTIAN GAMBOA C. ${ }^{1}$, JORGE MARTÍNEZ C. ${ }^{1}$ \\ Departamento de Cirugía Digestiva, Pontificia Universidad Católica de Chile, Santiago, Chile. \\ Servicio de Cirugía, Hospital Claudio Vicuña, San Antonio, Chile. \\ 3 Interno de Medicina. Universidad Andrés Bello, Santiago, Chile.
}

\begin{abstract}
Mesenteric lymphangioma causing volvulus. Report of one case

Lymphangiomas are rare benign lesions, most commonly seen in children and adolescents. Their intra-abdominal presentation is uncommon. We report a 19 years old male, presenting to the emergency room with abdominal pain associated with fever, vomiting and abdominal distension. There was a history of multiple previous consultations for abdominal pain. A plain abdominal X-ray examination suggested a bowel obstruction. At surgery a volvulus and dilation of the small bowel in relation to a vascular malformation was found, excising $40 \mathrm{~cm}$ of jejunum with an end-to-end intestinal anastomosis. The pathology report showed a Mesenteric Multicystic Lymphangioma. Presently, the patient is in good conditions.
\end{abstract}

Key words: Volvulus, bowel obstruction, lymphangioma.

\section{Resumen}

Los linfangiomas son lesiones benignas, de baja incidencia, más comunes en niños y adolescentes. Con muy baja frecuencia son intraabdominales y poseen presentación clínica variable, yendo desde el hallazgo clínico hasta pacientes con riesgo vital por abdomen agudo. Presentamos el caso de un paciente de 19 años, sin antecedentes mórbidos que acude a urgencias por dolor abdominal asociado a fiebre, vómitos y distensión abdominal; la radiografía simple es sugerente de obstrucción intestinal. En laparotomía exploradora se encuentra un vólvulo y dilatación del intestino delgado en relación a una malformación vascular y lesiones multilobuladas en mesenterio. Se resecan $40 \mathrm{~cm}$ de yeyuno y realiza anastomosis término-terminal. La histología reveló un Linfangioma Multiquístico Mesentérico. El paciente evoluciona en buenas condiciones generales y se mantiene control clínico e imagenológico seriado. Aunque infrecuente, es uno de los diagnósticos diferenciales de abdomen agudo. A pesar de su naturaleza benigna puede llegar a comprometer el pronóstico vital del paciente.

Palabras clave: Linfangioma, mesenterio, linfangioma quístico, vólvulo.

\footnotetext{
Correspondencia: Dr. Ricardo Yáñez M.

Marcoleta 352, Santiago, Chile. Fax 5623543462

E-mail: ryanezm@uc.cl
}

*Recibido el 11 de Julio de 2008 y aceptado para publicación el 14 de Diciembre de 2008. 


\section{Introducción}

Los linfangiomas son tumores benignos poco frecuentes que ocurren principalmente en niños, donde cerca de $90 \%$ pueden manifestarse antes de los tres años de edad, distribuyéndose igualmente en hombres y mujeres ${ }^{1}$. En pacientes jóvenes su presentación habitual es en cabeza, cuello y axila, ocurriendo esporádicamente en órganos parenquimatosos tales como tejido óseo, hígado y bazo, muchas veces de forma difusa o multifocal (linfangiomatosis) ${ }^{2}$. Durante la adultez pueden presentarse como lesiones superficiales (linfangioma cutáneo) o como linfangiomas intraabdominales, existiendo en este último caso una relación hombre: mujer de $3: 2^{3}$.

La característica clínica más frecuente del linfangioma abdominal consiste en una masa quística, palpable, blanda, habitualmente de crecimiento lento. Muchos pacientes pueden ser asintomáticos y ser diagnosticados incidentalmente durante el examen por una causa distinta o bien pueden presentarse de forma aguda como cuadro de riesgo vi$\mathrm{tal}^{3,4}$.

Nuestro objetivo es dar a conocer el caso de un paciente con Linfangioma Mesentérico Multiquístico, que presenta abdomen agudo en relación a la lesión y es resuelto quirúrgicamente.

\section{Reporte de caso}

Acude al Servicio de Urgencias del Hospital Claudio Vicuña de San Antonio paciente de 19 años de edad, hombre, con antecedentes de múltiples consultas por dolor abdominal desde los 15 años de edad, sin estudios diagnósticos. Consulta por dolor abdominal punzante en región periumbilical, irradiado a región dorsal, de inicio brusco, severo, asociado a náuseas, vómitos, anorexia y deposiciones líquidas. Destacaba taquicardia y fiebre. Abdomen distendido, con sensibilidad localizada en epigastrio y periumbilical, sin signos de irritación peritoneal ni masas palpables, ruidos intestinales abolidos. Radiografía simple de abdomen es sugerente de obstrucción intestinal (Figura 1). Exámenes de laboratorio: leucocitosis 13.000/uL, PCR de $31 \mathrm{mg} / \mathrm{dl}$, amilasemia y pruebas hepáticas dentro de rangos normales.

Se realiza laparotomía exploradora, encontrándose dilatación del intestino delgado, con coloración violácea y fino petequiado, signos sugerentes de sufrimiento de asa (Figura 2). El mesenterio del intestino delgado presentaba múltiples adenopatías y lesiones multilobuladas. Un segmento yeyunal, de $40 \mathrm{~cm}$, mostraba engrosamiento mesentérico de aspecto tumoral, color vinoso, con lóbulos que al ser puncionados sangraban profusamente. En relación a esta lesión vascular se observa vólvulo de intestino delgado, con colecciones de fibrina y ectasia linfática sobre el mesenterio. No se observó signos de compromiso colónico. Se resecó el segmento yeyunal (con pieza operatoria de 1.740 gr), con anastomosis término-terminal. Recibió profilaxis antibiótica con gentamicina y metronidazol.

En centro de mayor complejidad se realizó angioTAC que mostró dilatación y edema de asas intestinales, con ausencia de malformaciones vasculares remanentes (Figura 3).

En el postoperatorio evoluciona subfebril y con aumento de los parámetros inflamatorios, leucocitosis de $15.100 / \mathrm{uL}$ y PCR de $224 \mathrm{mg} / \mathrm{dl}$, se mantiene cobertura antibiótica de gentamicina y metronidazol intravenosos, con normalización de parámetros al décimo día. Al séptimo día postoperatorio inició realimentación oral con tránsito intestinal adecuado.

Al mes siguiente en TAC de abdomen y pelvis se observa masa sólida en raíz mesentérica, sin imágenes quísticas y con múltiples imágenes nodulares en polo inferior (Figura 4).

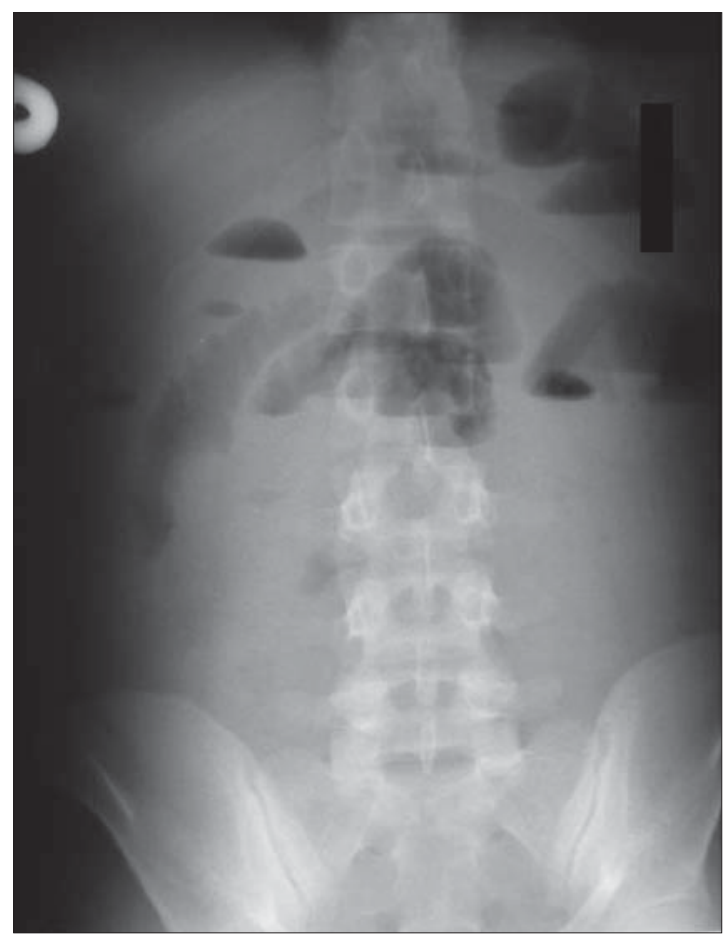

Figura 1. Radiografía simple de abdomen, de pie, en la cual se observan múltiples niveles hidroaéreos en intestino delgado, sin signos de perforación de víscera hueca ni edema de pared intestinal. 

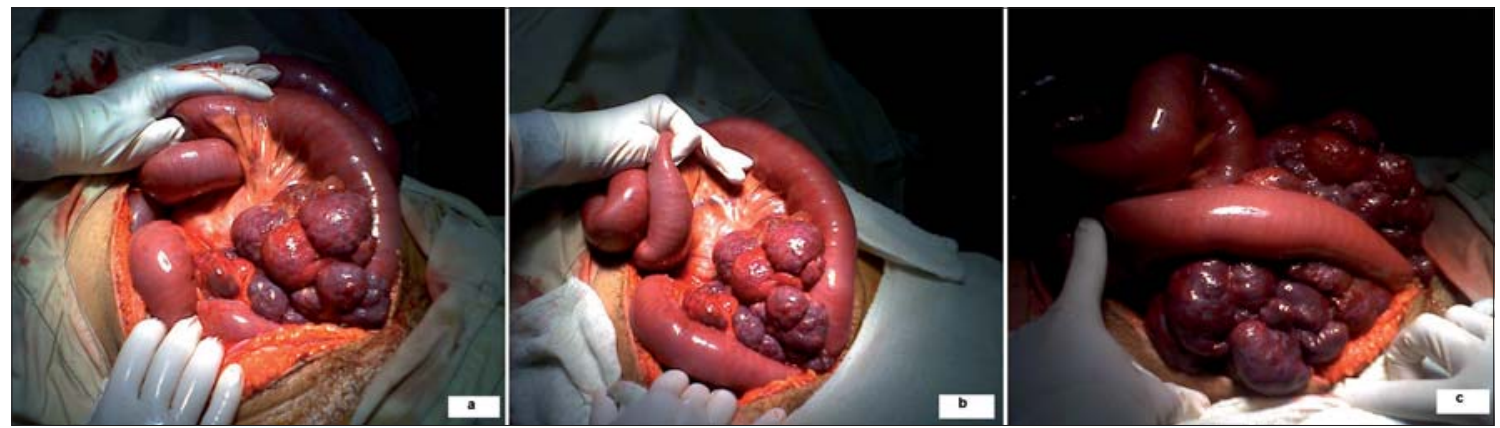

Figura 2. Intraoperatorio. a) se observa dilatación del intestino delgado en toda su extensión, con depósitos de fibrina en mesenterio. b) coloración violácea y fino petequiado en yeyuno. c) evidente dilatación intestinal, ectasia y depósitos de fibrina mesentéricos.
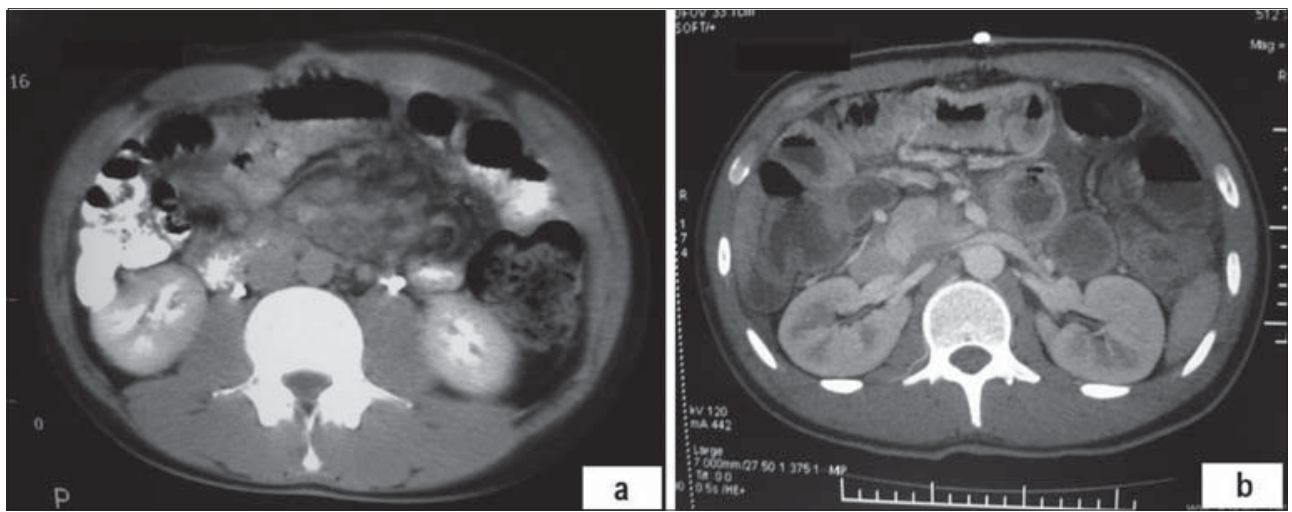

Figura 3. a) Angio-TAC del postoperatorio inmediato, donde se observa dilatación de asas intestinales asociado a edema de las mismas. Sin evidencia de lesiones remanentes. b) TAC abdominal tardío (un mes después) en el cual se observan asas intestinales de características normales.
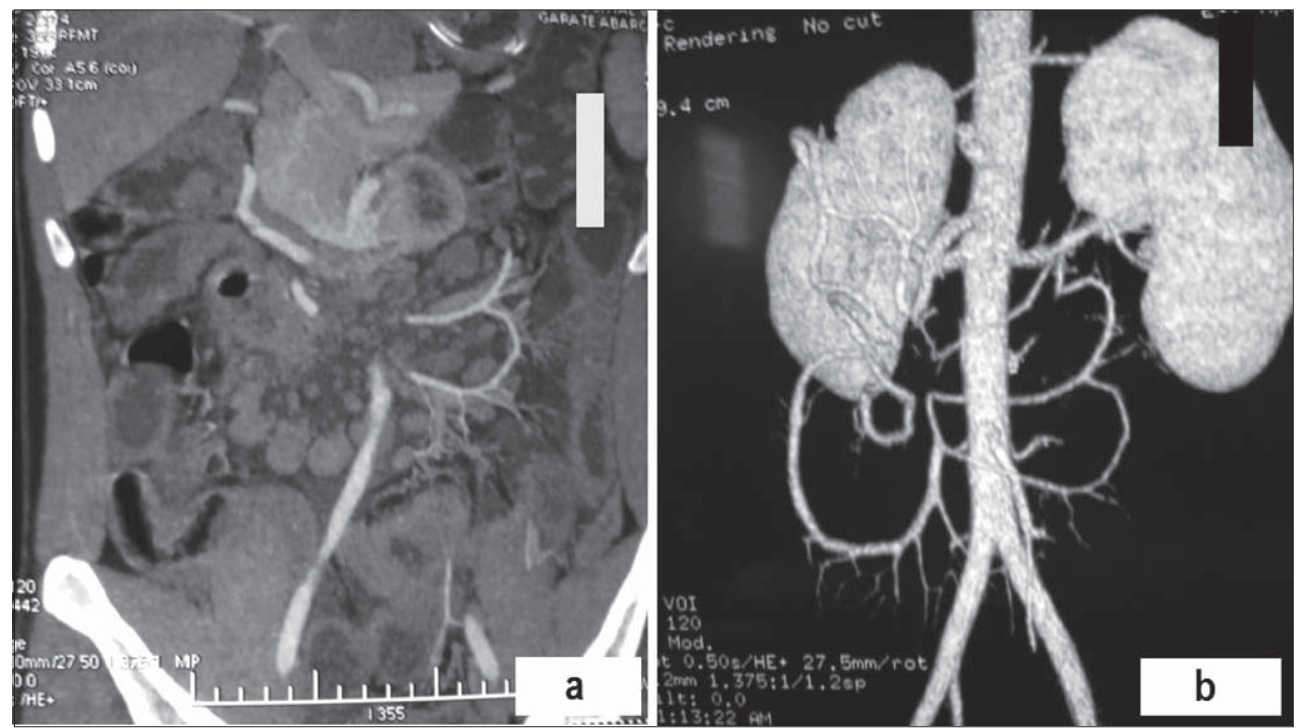

Figura 4. Angio-TAC abdominal. a) Masa de carácter sólido en la raíz del mesenterio, sin imágenes quísticas en su espesor ni signos de hipervascularización, con múltiples imágenes nodulares a nivel de su polo inferior. b) Vasos mesentéricos permeables y de calibre normal. 
El informe anatomopatológico describe un segmento de intestino delgado de $40 \mathrm{~cm}$ de longitud por $3 \mathrm{~cm}$ de diámetro, serosa moderadamente congestiva, mucosa marcadamente congestiva con pliegues conservados, se identifica mesenterio con proliferación vascular diferenciada madura con caracteres de Linfangioma Multiquístico.

Dado carácter benigno de la lesión se decide manejo conservador, con control clínico e imagenológico abdominal seriado, determinando necesidad de reintervenir frente a la aparición de signos de complicación o progreso de la enfermedad.

Actualmente se encuentra en buenas condiciones generales, sin recidiva de la lesión.

Aunque los linfangiomas son lesiones benignas, pueden causar mortalidad significativa ya sea por su gran tamaño, localización crítica y por la posibilidad de sobreinfectarse secundariamente ${ }^{4}$.

Los linfangiomas intraabdominales son lesiones aun menos frecuentes, presentando una incidencia cercana a 1/160.000 individuos y 1/100.000 hospitalizaciones. Se localizan en el mesenterio del intestino delgado y colon, aunque también puede tener ubicación retroperitoneal; corresponden al 7\% de los quistes abdominales ${ }^{5}$. En un estudio de 139 casos de linfangiomas mesentéricos se observó una relación hombre: mujer 3:2, y niño: adulto también 3:2; el sitio más frecuente fue el mesenterio del intestino delgado (70,5\%), seguido por el mesocolon $(26,2 \%)^{6}$. La sintomatología puede ir desde el dolor abdominal crónico hasta la presentación como abdomen agudo debido a perforación, infección, torsión o ruptura de víscera, presentándose como abdomen agudo u obstrucción intestinal el $25 \%$ de los casos en adultos?

La etiología de los linfangiomas es probablemente una malformación primaria donde ocurre un secuestro del tejido linfático durante el desarrollo embriológico, lo que explicaría que se presenten principalmente en niños; sin embargo, se ha sugerido también que el trauma abdominal, la obstrucción linfática, procesos inflamatorios, cirugía o radioterapia pudieran causar una formación secundaria de este tumor. Esto último explicaría casos de linfangiomas en pacientes mayores de 60 años que previamente han presentado exámenes imagenológicos normales años antes del diagnóstico ${ }^{8,9}$.

En 1887 Wegner clasificó a los linfangiomas en tres grupos: a) simples o capilares compuestos por vasos linfáticos de pequeño calibre y paredes delgadas, localizados superficialmente en la piel; b) cavernosos, consistentes en grandes canales linfáticos de paredes gruesas y c) quísticos (higromas) que presentan grandes espacios quísticos rodeados por tejido colágeno, linfoide y escaso músculo liso, en general no presentan conexión con el tejido linfático normal adyacente ${ }^{10}$. Según Henzel et al, sólo los linfangiomas cavernosos y quísticos presentan localización intraabdominal ${ }^{11}$.

El diagnóstico diferencial incluye hemangiomas cavernosos, cuando presentan hemorragia secundaria, mesoteliomas, tumores pancreáticos $\mathrm{y}$, en otro contexto, un quiste hidatídico peritoneal ${ }^{3,12}$.

En la radiografía simple de abdomen, sin preparación, puede observarse una opacidad de tonalidad hídrica que refuerza las asas intestinales. La apariencia ecográfica de los linfangiomas es variable, pero la mayoría de las veces es descrita como una masa quística con múltiples septos delgados. En la tomografía computada (TAC) se observan característicamente masas uni o multiloculares que contienen septos de grosor variable; con el contraste se observa refuerzo en la pared y permite precisar la anatomía del linfangioma, localización, extensión y relación con los órganos vecinos. Asimismo se ha visto que la angiografía puede revelar desplazamiento o disminución del lumen arterial por el tumor, sin llegar a mostrar su vasculatura. La resonancia magnética precisa de manera más específica el contenido de la lesión, en caso de contener líquido existe una hiposeñal en T1 e hiperseñal en T2 que se refuerza en la fase tardía de T2. En varios reportes se ha utilizado la aspiración con aguja fina, donde se observa un fluido lechoso que contiene células linfoides, método útil para confirmar el diagnóstico preoperatorio en los cuales sea técnicamente factible el procedimiento $0^{4,13,14}$.

Macroscópicamente la lesión está constituida por quistes en racimo de uvas, de número y tamaño variables, independientes o comunicados entre ellos, en general el tamaño de la lesión va de los 5 a 20 cm de diámetro, en un $25 \%$ son uniloculares y $75 \%$ polilobulares multiquísticos. La histología muestra en general un conglomerado de espacios linfáticos dilatados coexistentes de formaciones ganglionares y un importante desarrollo hemangiomatoso ${ }^{15}$.

La mayoría de las lesiones requiere tratamiento quirúrgico. El tipo de procedimiento varía según la localización de la lesión y el resultado cosmético esperado, en el caso de los linfangiomas de cabeza y cuello; y se guiará por la extensión de la lesión y compromiso de estructuras vecinas en el caso de los linfangiomas mesentéricos. La escisión completa del tumor es el tratamiento óptimo, aun incluyendo órganos adyacentes, ya que la resección incompleta puede llevar a la recurrencia de la lesión incluso varios años más tarde con un riesgo de recidiva de 10 a $15 \% \%^{1-4,8-12}$.

Otros tratamientos realizados si la cirugía radical no es técnicamente posible han sido las inyecciones esclerosantes con bleomicina u OK-432 en tumores irresecables como lesiones mesentéricas difusas ${ }^{15}$. 
En conclusión, los linfangiomas intraabdominales son tumores muy poco frecuentes que ocurren en el mesenterio del intestino delgado o colónico, la sintomatología puede ser muy variada, presentándose en nuestro caso como abdomen agudo que requirió cirugía de urgencia por una causa obstructiva secundaria al tumor, cuyo tratamiento de elección fue la escisión de éste.

\section{Referencias}

1. Rieker RJ, Quentmeier A, Weiss C, Kretzschmar U, Amann K, Mechtersheimer G, et al. Cystic lymphangioma of the small-bowel mesentery: case report and a review of the literature. Pathol Oncol Res 2000; 6: 146-148.

2. Seki H, Ueda T, Kasuya T, Kotanagi H, Tamura T. Lymphangioma of the jejunum and mesentery presenting with acute abdomen in an adult. J Gastroenterol 1998; 33: 107-111.

3. Kably A, Moumen M, Raissouni N, Benjelloun N, Mehhane M, Abi F, et al. Le lymphangiome kystique du mésentère et de l'épiploon. À propos de deux cas. Gynecol Obstet Fertil 2003; 31: 136-138.

4. Mabrut JY, Grandjean JP, Henry L, Chappuis JP, Partensky C, Barth X, et al. Les lymphangiomes kystiques du mésentère et du méso-côlon. Prise en charge diagnostique et thérapeutique. Ann Chir 2002; 127: 143-149.

5. Chung MA, Brandt ML, St-vil D, Yazbeck S. Mesenteric cyst in children. J Pediatr Surg 1991; 26: 1306-1308.

6. Tsukada H, Takaori K, Ishiguro S, Tsuda T, Ota S,
Yamamoto T. Giant cystic lymphangioma of the small bowel mesentery: report of a case. Surg Today 2002; 32: 734-737.

7. Chin S, Kikuyama S, Hashimoto T, Tomita T, Hasegawa T, Ohno Y. Lymphangioma of the jejunal mesentery in an adult: a case report and a review of the Japanese literature. Keio J Med 1993; 42: 41-43.

8. Reyes I, Rossel G, Pacheco A, Parada X, Casanova ME. Linfangioma de intestino delgado. Rev Chil Cir 2004; 56: 66-70

9. De Herdt P, Hoskens C, Van Herreweghe W, Verhelst A, Neetens I, Eyskens E. Abdominal cystic lymphangioma. A case report and a review of the literature. J Belge Radiol 1990; 73: 37-40.

10. Wegner G. Ueber lymphangiome. Archiv fur klinische Chirurgie 1887; 20: 641.

11. Henzel JH, Pories WJ, Burget DE, Smith JL. Intraabdominal lymphangiomata. Arch Surg 1966; 93: 304308.

12. de Vries JJ, Vogten JM, de Bruin PC, Boerma D, Van de Pavoordt HD, Hagendoorn J. Mesenterical lymphangiomatosis causing volvulus and intestinal obstruction. Lymphat Res Biol 2007; 5: 269-273.

13. Protopapas A, Papadopoulos D, Rodolakis A, Markaki $\mathrm{S}$, Antsaklis A. Mesenteric lymphangioma presenting as adnexal torsion: case report and literature review. J Clin Ultrasound 2005; 33: 90-93.

14. Redondo P. Vascular malformations (I). Concept, classification, pathogenesis and clinical features. Actas Dermosifiliogr 2007; 98: 141-158.

15. Acevedo JL, Shah RK, Brietzke SE. Nonsurgical therapies for lymphangiomas: a systematic review. Otolaryngol Head Neck Surg. 2008; 138: 418-424. 